\title{
Comparison of Alcohol Ablation with Depomedrol Injection in Medial Branch Neurotomy for the Treatment of Recurrent lumbar Facet Joint Pain
}

\author{
Khalid Ali Khaleel ${ }^{1}$, Zaid Al-Attar ${ }^{2 *}$
}

${ }^{1} \mathrm{MBChB}$, DA FICMS Senior anesthesiologist in Dept. of Anesthesia, Intensive Care and Pain Management, Neuroscience hospital / Baghdad /Iraq

${ }^{2} \mathrm{MBChB}, \mathrm{PhD}$ (pharmacology) Lecturer, Dept. of Pharmacology, Al-Kindy College of Medicine / University of Baghdad / Baghdad /Iraq

*Corresponding author: Zaid Al-Attar

Abstract

Chemical denervation is not recommended as part of the routine care of chronic non-cancer pain. This study was performed to compare the effects of alcohol ablation (AA) with depomedrol injection (DI) in patients with recurrent lumbar facet joint pain. Methods: a hundred patients with recurrent lumbar facet joint pain defined as a numeric rating scale. Patients complaining of a backache origin were selected. Then, a test was done by implementing the $2 \mathrm{ml} 2 \%$ lidocaine as a diagnostic test to check if pain disappears. Then, when pain is confirmed due to lumbar cause, 50 patients (the first group) were given depomedrol $20 \mathrm{mg}$ which is injected at each nerve level of the first group. While the second group (50 patients) was given $0.5 \mathrm{ml} 50 \%$ alcohol at each nerve level. Both groups were followed at regular intervals for 2 years. The patients were evaluated in terms of Visual Analogue Scale (VAS) and Revised Oswestry backache disability index (ODI). The results of our study show clearly that alcohol is more effective than depomedrol in lowering pain of lumbar origin. Conclusion: Alcohol is more effective in treatment of lumbar facet joint pain than corticosteroids and reduces the recurrence rate.

Keywords: Ablation technique, alcohol, Facet joint, Depomedrol, Recurrence.

Copyright @ 2020: This is an open-access article distributed under the terms of the Creative Commons Attribution license which permits unrestricted use, distribution, and reproduction in any medium for non-commercial use (NonCommercial, or CC-BY-NC) provided the original author and source are credited.

\section{INTRODUCTION}

Nerve blocks find extensive diagnostic and therapeutic applications. It is an essential skillset for pain specialists and anesthesiologists. The essence of these applications is that pain signals have to be conducted, transmitted, and modulated in the peripheral and central nervous systems. Blocking these processes in the peripheral or central nervous system would lead to pain relief or prevent pain signals from reaching the cortical level. For diagnostic purpose, specific nerves can be blocked to test if pain is generated from a particular anatomical structure/region such as the facet joints or sacroiliac joints. For therapeutic purpose, nerve blocks are often used to manage acute pain from medical procedures, surgeries, and trauma. In subacute and chronic pain settings, nerve blocks are performed to provide pain relief for days, weeks, or months.

Nerve blocks typically provide pain relief for limited duration. When a longer term of pain relief is desired, nerve ablation may be performed to provide pain relief for an extended period of time. It is usually employed when more conservative modalities of treatment have failed to effectively manage severe and debilitating pain conditions. Clinically, it is achieved by chemical neurolysis, radiofrequency ablation, or cryoneurolysis. These interventions cause degeneration of the nerve fibers and interference with the transmission of pain signals. In these procedures, the basal lamina (a thin protective layer around the nerve fiber) is preserved so that, as a damaged fiber regrows, it travels within its basal lamina tube and connects with the correct target of innervation, and function may be restored. In contrast to neuroablation, surgical cutting of a nerve (neurectomy) severs these basal lamina tubes. Without intact basal lamina to channel the regenerating fibers, a painful neuroma or deafferentation pain may develop over time. Another disadvantage of neurectomy is that surgical lesion usually requires an incision and is much traumatic to tissues surrounding the target nerve. This is why the neurolytic approach is usually preferred over surgical intervention [1]. 
Chemical neurolysis, as a treatment for facet joint pain syndrome, is generally accepted only for the relief of patients experiencing chronic intractable pain. Potential complications arising from chemical neurolysis of the peripheral nerves include necrosis of the skin and other non-target tissue, neuritis, anesthesia dolorosa, and prolonged motor paralysis [2]. The risks of chemical neurolysis are considered to outweigh its benefits. Therefore, the American Society of Anesthesiologists' Task Force on Chronic Pain Management and American Society of Regional Anesthesia and Pain Medicine recommended in 2010 that chemical denervation should not be used in the routine care of non-cancer patients with chronic pain [3]. Chemical ablation using alcohol may be a solution for short-lasting.

Chemical neurolysis using depomedrol have been tried in the past in cases of pancreatic cancer and was found to be less effective than alcohol [4].

Steroids are widely used in nerve root blocks, epidural injections, and facet joint injections in an attempt to provide temporary relief from pain. When selective nerve root blocks (SNRBs) are performed for disk herniations, the goal is to provide pain relief for enough time to allow the extruded disks to shrink. In more than $70 \%$ of disk herniations, the disk material resolves on its own, given enough time; however, this process can take well over a year. Despite this widespread use, for many years, the lack of randomized controlled trials resulted in questions about the efficacy of steroid injections, and the result of one study suggested that there was no difference between saline and steroids in relieving pain in the facet joint [5].

\section{THE AIM OF STUDY}

To compare the efficacy of alcohol versus depomedrol in facet joint denervation

\section{PATIENTS AND METHODS}

Patients complaining of a backache origin were selected. All of them were consented about the intervention and possible results and complications. They were situated in a prone position. Local anesthesia was implemented under aseptic technique with IV fluid and monitoring. Then, a test was done by implementing the $2 \%, 2 \mathrm{ml} 2 \%$ lidocaine as a diagnostic test to check if pain disappears. Then, when pain is confirmed due to lumbar cause, a medical branch block was performed for the 50 patients (the first group) using depomedrol 20 $\mathrm{mg}$ which is injected intra-articularly.

A medial branch block was performed for second group (50 patients). Each patient was given 0.5 $\mathrm{ml} \mathrm{50 \%} \mathrm{alcohol} \mathrm{at} \mathrm{each} \mathrm{nerve} \mathrm{level.}$

The injection of both depomedrol and alcohol was performed using a curved probe under ultrasound guide.

Both groups were followed at regular intervals for 2 years. The patients were evaluated in terms of VAS and Revised Oswestry backache disability index (ODI).

Statistical analysis was done using Graph Pad prism 8 software package by implementing the one-way ANOVA for each of depomedrol and alcohol alone. Then implementing two-way ANOVA for comparisons between depomedrol and alcohol.

\section{RESULTS}

Depomedrol has shown a good response in terms of VAS (Figure 1). The pain score VAS decreased significantly as compared with 0 time.

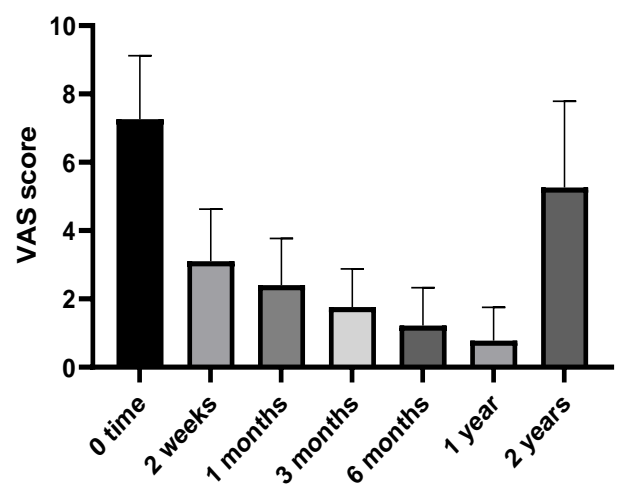

Fig.1: Effect of depomedrol alone on VAS using ANOVA test all results were highly significant $p<0.001$ as compared with 0 time

Regarding alcohol, again there was a good response in terms of VAS pain score with a high level of significance as compared with 0 times (Figure 2). 


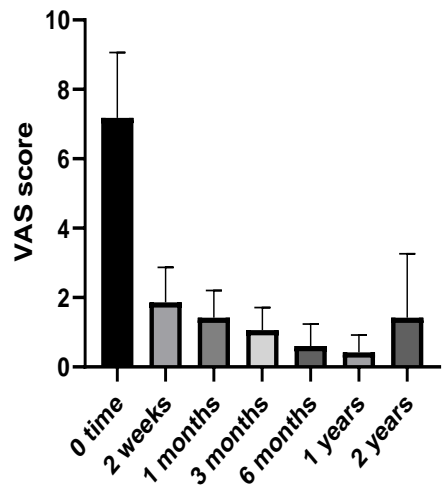

Fig. 2: Effect of alcohol alone on VAS score using one way ANOVA test all results were highly significant $p<0.001$ as compared with 0 time

Comparing alcohol and depomedrol in terms of VAS pain score has yielded supremacy of alcohol over depomedrol with a high significance levels on 2, 3 weeks and 2 years intervals (Figure 3).

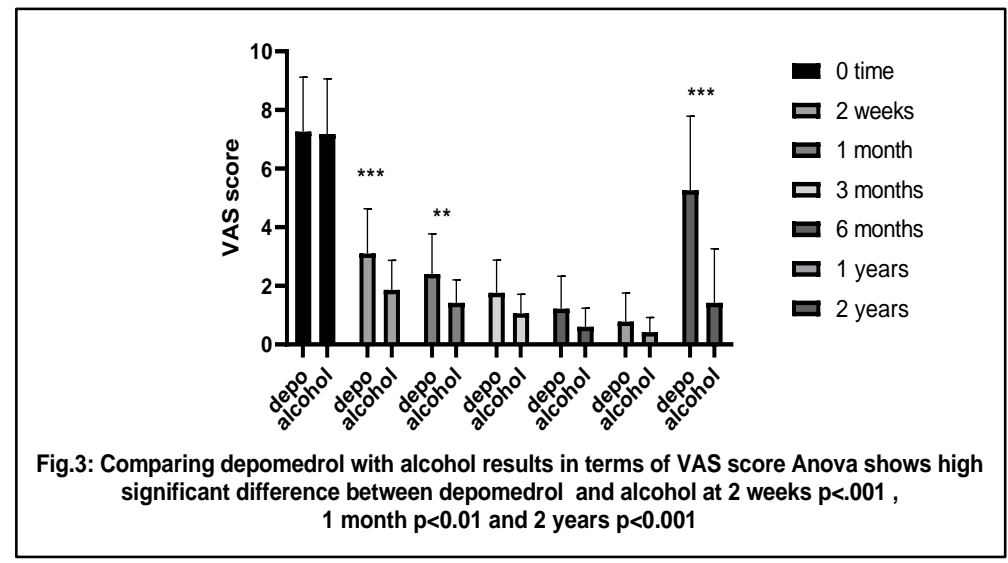

Then, by comparing depomedrol with alcohol in terms of Revised Oswestry backache disability index (ODI), there was a supremacy of alcohol over depomedrol with high statistical significance levels on 1,3,6 months and 2 years intervals (Figure 4).

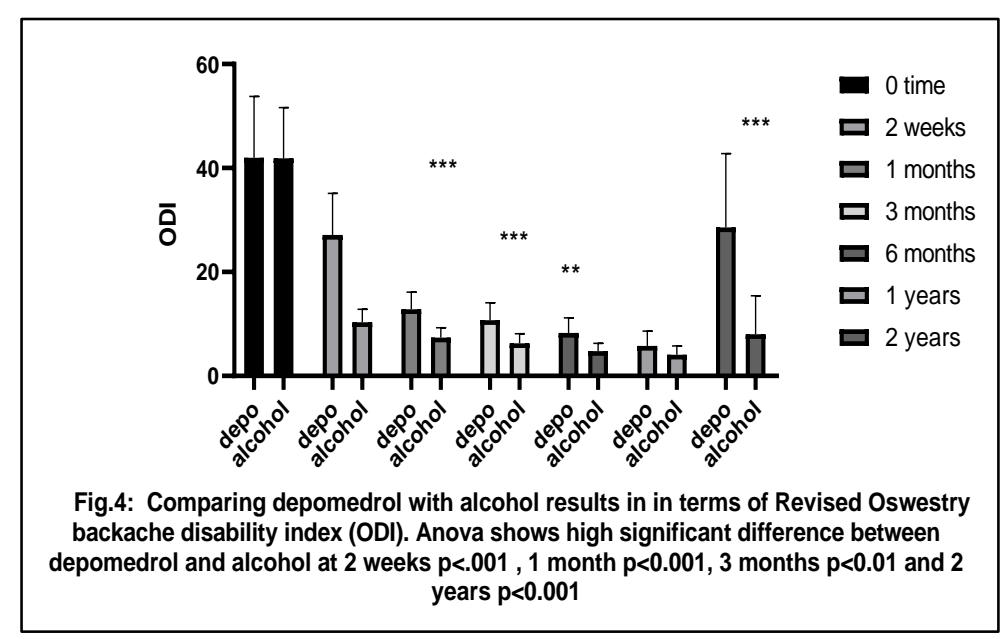

\section{DISCUSSION}

Spinal joint pain is a representative painful disorder which is determined by a diagnostic block rather than imaging studies. A dual infiltration of local anesthetics (for example, lidocaine and bupivacaine) into the medial branch of the posterior ramus is considered as a confirmatory diagnostic method after a history of referred pain and tenderness on the facet area. 
If the test shows a positive result of pain relief for different durations, a therapeutic nerve block is applied. However, if the effect of the therapeutic block lasts only for a short period and the pain recurs, a destructive procedure of nerve ablation or modulation may be an inevitable step for long-term pain relief [6].

They disrupt the transmission of pain signals for 3-6 months by causing Wallerian degeneration from the distal to the lesion [7]. Alcohol is the most commonly used agent for intractable visceral cancer pain to produce damage to the unmyelinated sympathetic chains and ganglia. However, potential complications arising from chemical neurolysis of the peripheral nerve include necrosis of the skin and other non-target tissue, neuritis, anesthesia dolorosa, and prolonged motor paralysis [8].

Up our knowledge there is clinical study comparing the efficacy of alcohol and depomedrol in management of lumbar pain. The results of our study show clearly that alcohol is more effective than depomedrol in lowering pain of lumbar origin.

The use of chemical neurolysis in chronic nonmalignant pain is not recommended. Nevertheless, it can be used in severe debilitated cases.

In lumbar pain cases, thermal radiofrequency waves are frequently applied to facet joints to prevent the recurrence. Comparing the efficacy of radiofrequency versus radiofrequency plus alcohol ablation has shown that using adjuvant alcohol is more effective. A study conducted in South Korea that lasted for 24-month follow-up after radiofrequency ablation (RFA) and AA, one and 17 patients, respectively, were without recurring thoracolumbar facet joint pain. The median effective periods in the RFA and AA groups were 10.7 (range 5.4-24) and 24 (range 16.8-24) months, respectively ( $\mathrm{p} \backslash 0.000)$. No significant complications were observed with the exception of injection site pain, which occurred in both groups [9].

\section{CONCLUSION}

In the management of lumbar facet joint pain, alcohol is better and safer with no morbidity as compared with depomedrol injection. Moreover, alcohol reduces the recurrence rate.

\section{REFERENCES}

1. Hoppenfeld JD. Fundamentals of Pain Medicine: How to Diagnose and Treat your Patients: Wolters Kluwer Health; 2014.

2. Fishman S, Ballantyne J, Rathmell JP, Bonica JJ. Bonica's management of pain Baltimore, MD: Lippincott, Williams \& Wilkins; 2010. Available from: http://site.ebrary.com/id/10822842.

3. Practice Guidelines for Chronic Pain Management: An Updated Report by the American Society of Anesthesiologists Task Force on Chronic Pain Management and the American Society of Regional Anesthesia and Pain Medicine*. Anesthesiology: The Journal of the American Society of Anesthesiologists. 2010;112(4):810-33.

4. Levy MJ, Topazian MD, Wiersema MJ, Clain JE, Rajan E, Wang KK, et al. Initial evaluation of the efficacy and safety of endoscopic ultrasound-guided direct Ganglia neurolysis and block. The American journal of gastroenterology. 2008;103(1):98-103.

5. Carette S, Marcoux S, Truchon R, Grondin C, Gagnon J, Allard Y. A controlled trial of corticosteroid injections into facet joints for chronic low back pain. The New England journal of medicine. 1991;325(14):1002-7.

6. Choi EJ, Choi YM, Jang EJ, Kim JY, Kim TK, Kim KH. Neural Ablation and Regeneration in Pain Practice. Korean J Pain. 2016;29(1):3-11.

7. Hsu M. Significance of Clinical Treatments on Peripheral Nerve and its Effect on Nerve Regeneration. Journal of Neurological Disorders. 2014;02.

8. Koyyalagunta D, Burton AW. The role of chemical neurolysis in cancer pain. Current pain and headache reports. 2010;14(4):261-7.

9. Joo YC, Park JY, Kim KH. Comparison of alcohol ablation with repeated thermal radiofrequency ablation in medial branch neurotomy for the treatment of recurrent thoracolumbar facet joint pain. Journal of anesthesia. 2013;27(3):390-5. 